\title{
O HABITAR DO ENSINAR E DO APRENDER EM TEMPOS DE PANDEMIA E A VIRTUALIDADE DE UMA EDUCAÇÃO OnLIFE
}

\author{
THE TEACHING AND LEARNING DWELLING IN PANDEMIC TIMES AND THE \\ VIRTUALITY OF AN OnLIFE EDUCATION
}

\author{
HABITAR DE ENSEÑAR Y APRENDER EN TIEMPOS DE PANDEMIA Y LA \\ VIRTUALIDAD DE LA EDUCACIÓN OnLIFE
}

Eliane Schlemmer

Universidade do Vale dos Sinos - Brasil

Lisiane Cézar Oliveira

Universidade do Vale dos Sinos - Brasil

Instituto Federal de Educação Ciência e Tecnologia do Rio Grande do Sul - Brasil

Janaina Menezes

Universidade do Vale dos Sinos - Brasil

\begin{abstract}
Resumo: O artigo apresenta uma pesquisa qualitativa, que se apropria do método cartográfico de pesquisa-intervenção para compreender rastros presentes nos contextos educacionais (educação básica, superior e pós-graduação) em tempos de pandemia. Problematiza o habitar do ensinar e do aprender na constituição de redes de conhecimento e de formação que articulam, a partir da pesquisa, a educação em diferentes níveis e a extensão. O objetivo é identificar pistas que possibilitem cocriar uma proposta de Educação OnLIFE, numa perspectiva ecossistêmica. Compreendemos o conceito de rede como o movimento conectivo que forma o social, sendo este composto por diferentes entidades biológicas, físicas e digitais (humanas e não humanas), que por atos conectivos vão tecendo essa rede. Dessa forma, nunca fica totalmente claro quem está atuando/agindo. O ato conectivo se dá no encontro operatório que pode acontecer no espaço geográfico e no espaço digital, de forma síncrona e assíncrona, por presenças plurais, nos hibridismos, onde ecologias diversas (inteligências humanas e não humanas) operam em rede. Essa compreensão traz em si, a superação de uma teoria da ação dualista (sujeito/objeto) e de centralidades (ora no conteúdo, no professor ou no estudante). A rede é então, o que emerge em atos conectivos transorgânicos, produto dos agenciamentos entre humanos e não humanos, que atuam mutuamente, conectando inteligências diversas, promovendo assim, a transubstanciação. Isso contribui para a superação de uma visão de mundo antropocêntrica, sujeitocêntrica e tecnocêntrica. Como resultado apresentamos pistas que permitem atualizar a virtualidade de uma Educação OnLIFE transubstanciada, enquanto ecossistema de inovação na educação.
\end{abstract}

Palavras-Chave: Ecossistema. Educação OnLIFE. pandemia 


\begin{abstract}
The article presents qualitative research that appropriates the cartographic method of intervention-research to understand the traces present in the educational contexts ( K-12, Higher and Postgraduate Education), in pandemic times. It problematizes the teaching and learning dwelling in the constitution of knowledge and development networks that articulate, from research, education at different levels. The objective is to identify clues that make it possible to cocreate an OnLIFE Education proposal, from an ecosystem perspective. We understand the concept of the network as the connective movement that forms the social, which is composed of different biological, physical and digital entities (human and non-human), which through connective acts weave this network. Thus, it is never completely clear who is acting. The connective act occurs in the operational encounter and this can take place both in geographic space, as in digital, synchronously or asynchronously, by plural presences, in hybridities, where intelligent ecologies operate (human and non-human intelligences) in network. This understanding brings the overcoming of a dualistic theory of action, sometimes content/teacher/studentcentered. The network is then what emerges from the trans organic connective acts, product of the agency between human and non-human actors, who act mutually, connecting diverse intelligences, thus promoting transubstantiation. That contributes to overcoming an anthropocentric, subject-centric and technocentric worldview. As a result, we present some clues that allow updating the virtuality of a transubstantiated OnLIFE Education, as an ecosystem of innovation in education.
\end{abstract}

Keywords: Ecosystem. OnLIFE Education. pandemic

Resumen: El artículo presenta una investigación cualitativa, que se apropia del método cartográfico de investigación-intervención para comprender las huellas presentes en contextos educativos (educación básica, educación superior y posgrado) en tiempos de pandemia. Se vuelve problemático el hábito de enseñar y aprender en la constitución de redes de conocimiento y formación que articulan la educación en diferentes niveles y extensión. Objetivando identificar pistas que permitan co-crear una propuesta de Educación OnLIFE, en una perspectiva ecosistémica. Entendemos el concepto de red como el movimiento conectivo que forma lo social, que está compuesto por diferentes entidades biológicas, físicas y digitales, que a través de actos conectivos tejen esta red. Por lo tanto, nunca está completamente claro quién está actuando. El acto conectivo se da en el encuentro operativo que puede suceder en el espacio geográfico y digital, de manera (a)sincrónica, a través de presencias plurales, en hibridaciones, donde diversas ecologías (inteligencias, humanas y no humanas) operan en red. Esta comprensión trae consigo la superación de una teoría dualista (sujeto/objeto) y centralidades (a veces en el contenido, ahora en el profesor o ahora en el alumno). La red es, por tanto, lo que emerge en los actos conectivos transorgánicos, producto de la agencia entre humanos y no humanos, que actúan mutuamente, conectando diversas inteligencias, promoviendo así la transubstanciación. Esto contribuye a superar una cosmovisión antropocéntrica, centrada en el sujeto y tecnocéntrica. Como resultado, presentamos pisats que permiten actualizar la virtualidad de una Educación OnLIFE transubstanciada, como ecosistema de innovación en educación.

Palabras clave: Ecosistema. Educación OnLIFE. pandemia

\title{
Problematizações do tempo presente
}

O habitar ${ }^{1}$ do ensinar e do aprender cultural e socialmente reconhecido se desenvolve predominantemente nos espaços físicos geograficamente localizados das instituições de Educação Formal. Nesses contextos, embora possam ser encontradas práticas pedagógicas e

\footnotetext{
${ }^{1}$ No contexto desse artigo, compreendemos o habitar, a partir de Di Felice (2009, p. 20) enquanto "conceito estratégico para pensar as transformações que interessam não apenas a nossa época e as nossas sociedades, mas, também, a nossa condição perceptiva e a nossa forma de sentir".
} 
metodologias que se originam de pedagogias relacionais ${ }^{2}$, parte significativa dessas ainda são herdeiras de pedagogias diretivas e instrucionistas ${ }^{3}$ que compreendem o conhecimento como algo externo ao sujeito e que precisa, portanto, ser inserido (input) em sua mente.

Nesse cenário, o professor se configura como aquele que detém o conhecimento acerca de um domínio específico, o qual passa a ser organizado em disciplinas, dividido em conteúdos, fragmentos cirurgicamente extraídos e assepticamente afastados de outros saberes. Esses são então "passados" aos estudantes. Desses, se espera uma escuta "atenta", memorização e reprodução em exercícios, cujo objetivo é "fixar o conteúdo". Na sequência, testes e provas são "aplicados", enquanto instrumentos avaliativos, sendo esses vigiados e milimetricamente protegidos à prova de fraudes. Os estudantes, são então testados e precisam provar que aquele conteúdo exposto pelo professor, está agora "impresso" em sua mente, sendo a aprendizagem relegada aquilo que acontece na res $\operatorname{cogitans}^{4}$, separada, pela visão dualista cartesiana, da res extensa ${ }^{5}$. Dessa forma, num contexto de dualismo entre o ensinar e o aprender, o sujeito e o objeto, e de centralidades, ora no conteúdo, ora no professor e ora no estudante, o conhecimento é compreendido enquanto produto final de uma representação e a partir de uma visão de mundo antropocêntrica.

Esse paradigma imprime o ethos da educação que por ora conhecemos, que se tornou ainda mais evidente com o surgimento da pandemia da COVID-19 e, com ela, a necessidade de desenvolver os processos de ensino e de aprendizagem em espaços digitais em rede. Isso nos leva a questionar: como as diferentes TD (tecnologias digitais) em rede têm ocupado espaço nesse território?

As TD dividem opiniões, mesmo depois da pandemia ter evidenciado que foram elas que nos mantiveram conectados, possibilitando a continuidade das interações sociais, nos diferentes âmbitos do nosso viver e conviver. Sem elas, nosso isolamento, sim, teria sido dito “isolamento social” e não físico, como o que de fato ocorreu.

Na emergência desse isolamento físico, surge o vocábulo "suspensão", o qual nos parece interessante para pensarmos o momento que vivemos, diante da pandemia da COVID-19 e, sobretudo, em relação às configurações emergenciais que os espaços de ensino e aprendizagem passaram a assumir. Mas o que de fato aconteceu com esses espaços?

\footnotetext{
2 fundamentadas numa concepção epistemológica interacionista.

3 fundamentadas numa concepção epistemológica empirista.

4 coisa pensante - mente (DESCARTES, 2009).

5 coisa externa - corpo (DESCARTES, 2009).
} 
Em seu duplo significado, o termo "suspensão" nos tensiona a pensar, enquanto ação de suspender e de interromper temporariamente, bem como elevação/flutuação, no sentido de olhar para uma realidade de uma perspectiva renovada. Essa última perspectiva nos tira de um dito lugar seguro ou normal, instigando-nos a enxergar para além do horizonte que não nos era permitido até então, seja tecnologicamente, metodologicamente e, principalmente, epistemologicamente. Isto provoca uma nova compreensão do que seja social e cultural, o que compreendemos por social em rede. Sendo a educação um processo essencialmente social, o que significa aprender e ensinar em rede?

A suspensão das atividades presenciais físicas nas instituições de ensino em função da pandemia da COVID-19 nos trouxe a sensação muito bem colocada por Bruno Latour (2020, p. 18) de que "quando o tapete é tirado de nossos pés, você entende num segundo que terá que se preocupar com o assoalho". Para o autor, a única saída para enfrentar essa situação atípica é projetarmos ações para um futuro próximo e descobrirmos juntos, em rede, qual território é habitável, ou seja, quais espaços precisam ser criados e habitados e com quem podemos compartilhá-los, uma vez que os atores não são compreendidos como apenas humanos, mas enquanto entes de diferentes materialidades, feitas de átomos e de bits.

É nesse contexto que esse artigo, a partir da análise do movimento da educação em tempos de pandemia, tanto no âmbito da educação básica quanto superior, na graduação e pósgraduação stricto sensu, problematiza o habitar do ensinar e do aprender na constituição de redes de conhecimento e formação que articulam a educação em diferentes níveis, a pesquisa e a extensão, numa perspectiva ecossistêmica. A pesquisa de natureza qualitativa se apropria do método cartográfico de pesquisa intervenção com o objetivo de apresentar pistas que nos permitam atualizar a virtualidade de uma Educação OnLIFE, entendida como a educação ligada, conectada $(O n)$ e instigada pelas problematizações da vida (LIFE) no tempo presente.

\section{A virtualidade de uma Educação OnLIFE}

Ao refletirmos sobre a Educação Formal e os espaços geográficos na qual acontece, chegamos aos muros que separam as instituições educacionais e às paredes que limitam a aula à sala de aula, cercando as aprendizagens. Podemos relacionar essa perspectiva com a metáfora dos muros que cercavam as cidades antigas e medievais utilizada por Di Felice (2009). Embora no âmbito das cidades essa separação física tenha deixado de existir, o homem não conseguiu mais fazer parte da natureza e, separado, reduziu tudo o que não era humano a matérias-primas e aos objetos. 
No âmbito da Educação, podemos dizer que os muros das instituições e as paredes das salas de aula, que ainda existem e persistem, separam as aprendizagens formais das aprendizagens num mundo em rede, estando as primeiras reduzidas ao espaço interno da sala de aula, aos materiais instrucionais definidos pelo professor, ocupando ambos a centralidade do processo e ignorando, portanto, o ecossistema da biodiversidade do qual o homem é parte, nessa rede que hoje é também tecida pela técnica. São justamente a técnica e a tecnologia que possibilitam hibridizar esses diferentes mundos - físico, biológico e digital -propiciando que a aprendizagem se prolongue para além dos muros das instituições, das paredes da sala de aula e do próprio conceito de aula, em fluxos por diferentes plataformas digitais que possibilitam um habitar atópico do ensinar e do aprender, instigando-nos, então, para a construção de uma Educação OnLIFE.

O termo OnLIFE emergiu da problematização sobre o que significa ser humano em uma época hiperconectada. A partir dessa problemática, teve origem o projeto OnLIFE Initiative, desenvolvido por um grupo de pesquisadores liderado por Luciano Floridi. Como resultado da pesquisa, foi publicado em 2015 o documento The OnLIFE Manifesto: Being Human in a Hyperconnected Era (FLORIDI, 2015a). O objetivo do manifesto consistiu em compreender as consequências das transformações ocasionadas pela explosão das redes digitais em políticas públicas e apontar a necessidade de repensar conceitos como autoria, privacidade e responsabilidade (FLORIDI, 2015a). Para Floridi (2015b), o OnLIFE se refere a essa nova experiência de realidade hiperconectada que emerge do imbricamento entre o online e o off line.

No “The OnLIFE Manifesto: Being Human in a Hyperconnected Era”(FLORIDI, 2015a), as TD são assumidas como 'forças ambientais' que alteram quem somos, nossas interações e a forma como nos socializamos, a concepção que temos da realidade, bem como as nossas interações com essa realidade. Segundo o texto, essa hiperconectividade do mundo provoca 4 grandes transformações que se referem a) ao apagamento da fronteira entre a realidade e a virtualidade; b) à distinção difusa entre humano, máquina e natureza; c) à passagem da escassez de informação para a informação abundante; d) à passagem da ênfase nas propriedades individuais e binárias para a primazia das interações, processos e redes (FLORIDI, 2015b).

A partir do manifesto, que apresenta a sociedade hiperconectada e OnLIFE, somos instigados a refletir sobre os diferentes domínios sociais (para além dos humanos), a partir da compreensão proposta por Di Felice (2017) de ato conectivo em detrimento à social e, em especial, refletir sobre a Educação diante dessa realidade. Nesse contexto, Schlemmer (2020a), Moreira e Schlemmer (2020) e Schlemmer, Di Felice e Serra (2020) tomam emprestado o termo OnLIFE de Floridi (2015) e, na relação com os estudos de Serres (2013), Morin (2011), Di 
Felice (2009, 2017), Kastrup (2001, 2015) e Haraway (2014, 2015, 2016a, 2016b), apresentam algumas pistas que podem nos auxiliar na compreensão dessa virtualidade de uma Educação OnLIFE. Esses autores também ajudam a pensar acerca das mudanças que são necessárias no paradigma educacional vigente, para que Educação OnLIFE possa emergir e, portanto, se atualizar, bem como o que se altera em relação aos processos de ensino e de aprendizagem.

De acordo com Schlemmer, Di Felice e Serra (2020), a hibridização do mundo físico, do mundo biológico e do mundo digital que produz essa nova realidade hiperconectada, as experiências vividas pela educação em tempos de pandemia, bem como os questionamentos que delas emergem constituem um território fértil para que possamos construir uma Educação OnLIFE, a qual compreende:

- a) as TD em rede enquanto 'forças ambientais', conforme referido por Floridi (2015b), as quais, no campo da educação, modificam professores e estudantes, a maneira como interagem entre si, alterando os processos de ensino e de aprendizagem, a compreensão da realidade e as formas como se conectam com essa realidade que os cerca. Assim, as TD deixam de ser compreendidas enquanto ferramentas, instrumentos, recursos e apoio a serem usadas na Educação, e passam a ser compreendidas como potência para a emergência de ecologias inteligentes e de ecossistemas educativos que afetam a forma como ensinamos e como aprendemos;

- b) a rede como um novo tipo de complexidade ${ }^{6}$ ecossistêmica que é sempre um conjunto de redes de redes, isto é, um conjunto de inter-relações cujos limites ou perímetros são ilimitados e remetem, sobretudo, a entidades distintas humanas e não humanas (DI FELICE,2011);

- c) a educação como ligada, conectada (On) e instigada pelas problematizações da vida (LIFE) no tempo presente, em um contexto de aprendizagem inventiva (KASTRUP, 2001; 2015) e ecologias inteligentes que superam, portanto, o dualismo entre a educação off line e a educação online, compreendendo-se OnLIFE; d) uma arquitetura ecossistêmica conectiva - humanos, máquinas e natureza - que possibilita um habitar atópico do ensinar e do aprender e busca a superação de uma compreensão de mundo antropocêntrica, sujeitocêntrica e antropomórfica.

A combinação da 1) problematização do tempo presente, nessa nova realidade hiperconectada, com suas 2) TD em rede, compreendidas enquanto forças ambientais e; 3) o processo de digitalização do mundo, tem tensionado as epistemologias, teorias, metodologias e

\footnotetext{
${ }^{6}$ Morin (2011), Deleuze e Guattari (1995), Serres (2013), Latour (2012)
} 
práticas pedagógicas, que por ora problematizam as pedagogias vigentes. Essas pedagogias não conseguem abranger a complexidade presente nessa realidade hiperconectada, uma vez que limitam o agir apenas aos humanos, numa visão antropocêntrica do mundo.

Nesse contexto, Schlemmer (2020a) e Schlemmer, Di Felice e Serra (2020) apresentam algumas mudanças necessárias no paradigma educacional vigente para que a Educação OnLIFE possa emergir:

- a compreensão de que a educação acontece por meio de relações que se estabelecem em rede, por atos conectivos entre humanos e não humanos, portanto, transorgânicos. No caso das TD, elas não se reduzem a máquinas que operam segundo instruções humanas, mas possuem uma inteligência de máquina (IA) que interage, atua e se acopla com o humano, podendo mudar de status de forma autônoma, por meio de mineração de uma infinidade de dados e da realização de Learning Analytics, o que possibilita termos ambientes adaptativos e personalizados à diferentes necessidades de aprendizagem;

- a superação do binômio Sujeito-Objeto (S-O). A educação é ato conectivo em REDE e se dá na complexidade entre humanos, máquinas e natureza, ou seja, num ecossistema conectivo;

- a compreensão de que o ensino e a aprendizagem em rede implicam em não centralidades, seja ela no professor, no conteúdo ou no estudante;

- a compreensão de TD em rede enquanto 'forças ambientais' que potencializam o habitar atópico do ensinar e do aprender coengendrados, propiciados por Plataformas Ecossistêmicas Conectivas Inventivas (SCHLEMMER, DI FELICE, 2020);

- a emergência de pedagogias conectivas em rede que potencializem o habitar atópico do ensinar e do aprender coengendrados;

- o imbricamento da educação presencial física com a educação online, potencializando a constituição de Espaços de Convivência e Aprendizagem Híbridos (ECAH) que pressupõem um hibridismo quanto a espaços, tempos, tecnologias, presenças, culturas, linguagens e modalidade, ou seja, o nosso desafio agora não é o digital, mas sim o híbrido e multimodal;

- a necessidade de inovação nas práticas pedagógicas, de forma que essas práticas, a partir da problematização do mundo presente e potencializadas pelos ECAH, possam ser simpoiéticas, imersivas e gamificadas;

- a compreensão de que a realidade atual exige de nós muito mais do que resolver problemas, implica a problematização, provocada pelo mundo, gerando os 
desequilíbrios, os breakdowns ${ }^{7}$. Isto significa que estamos frente a uma situação de aprendizagem inventiva e não simplesmente ativa, que trabalha na perspectiva de resolução de problemas, potencializando, assim, a emergência de metodologias inventivas em nível de invenção de problemas;

- a compreensão de que o digital também é real, sendo a 'matéria' não o átomo, mas o bit;

- o entendimento de que a inovação não está nem no digital, nem no átomo, mas no virtual enquanto potência que surge na e da REDE conectiva entre humanos e não humanos e se atualiza na inventividade de práticas pedagógicas, metodologias, currículos, pedagogias;

- a compreensão de que o específico dessa nova realidade, o que faz com que ela seja hiperconectada, é o digital em rede, sendo o virtual - de virtus, isto é, potência - aquilo que emerge dessa nova realidade e, enquanto potência, não é específico do digital, mas sempre existiu na história da humanidade.

Nesse sentido, desejamos discutir a seguir, a metodologia que dá origem a essa pesquisa cujo objetivo foi de buscar pistas que nos permitissem atualizar a virtualidade da Educação OnLIFE compreendida em uma perspectiva ecossistêmica.

\section{Hódos-meta: Os movimentos da pesquisa}

A pesquisa que originou esse artigo é de natureza qualitativa e se apropria da cartografia para compreender os rastros, que são sinais deixados em um percurso, presentes em dois grupos de formação docente: um na educação básica e outro na educação superior e pós-graduação stricto sensu em tempos de pandemia. Proposto por Kastrup (2007), Passos e Barros (2015), Passos, Kastrup e Escóssia (2015) e Passos, Kastrup e Tedesco (2016), esse método se distancia do paradigma da representação, dado que na sua apropriação não são pré-definidas atividades, regras, padrões ou procedimentos que enquadrem a pesquisa. Segundo Passos, Kastrup e Escóssia (2015), a cartografia se apresenta como uma hódos-meta que propõe uma reversão metodológica em detrimento do meta-hódos, sendo a primeira é apresentada como o caminhar que traça no percurso suas metas e, a segunda, predeterminada por metas dadas de partida.

A relevância da cartografia se encontra no sentido de acompanhar um processo de pesquisa, um território e seus atores/entes e não representar um objeto, ou seja, trata de

\footnotetext{
${ }^{7}$ rachaduras no fluxo cognitivo habitual, nos forçando a pensar
} 
investigar um processo de produção de significado, sem buscar estabelecer um caminho linear para atingir um fim. Em contrapartida, questionados por metodologistas mais cartesianos, o que por sua vez poderia parecer uma ação sem direção, segundo Passos e Barros (2015), o método tem como diretriz cartográfica a orientação por pistas, que tem por motivação apoiar o percurso de quem pesquisa (cartógrafo), da pesquisa (e intervenção), considerando: o objeto de pesquisa, o pesquisador e os resultados.

Para a cartografia, segundo Barros e Barros (2016, p.178), analisar é "um procedimento de multiplicação de sentidos e inaugurador de novos problemas"; já para Rodrigues (2012, p. 39), pode constituir "palavra de desordem, de invenção, de conexão, de transgressão, na contracorrente dos sedentarismos "solucionadores"'. Para analisar, é preciso estar no campo, 'estar' não reduzido a uma presença física e geográfica no território de observação, mas a uma presença do cartógrafo enquanto atenção àquilo que é cultivado durante um percurso, ou seja, produzido e não meramente coletado ao final de etapas preestabelecidas.

O método de pesquisa-intervenção, segundo Alvarez e Passos (2015), apresenta quatro movimentos no sentido de apoiar o processo da atenção do pesquisador cartógrafo e que orientam o percurso da pesquisa: o rastreio o toque, o pouso e o reconhecimento atento, conforme apresentados na Figura 1.

No escopo desse artigo, o território da pesquisa compreende grupos de formação de professores, nos diferentes contextos educacionais - Educação Básica e Educação Superior, graduação e pós-graduação stricto sensu - em tempos de pandemia. Os dispositivos apropriados para a produção e cultivo dos dados foram os diálogos realizados em grupos do WhatsApp, criados especificamente para as formações e registros em texto, áudio, imagem e vídeo contidos nos mesmos, num período que compreende março a setembro de 2020. Os quatro movimentos da atenção do cartógrafo possibilitaram encontrar os rastros deixados pelos professores, no que tange aos processos de ensino e de aprendizagem desenvolvidos com TD em rede. 
Figura 1 - Movimentos de atenção do cartógrafo

\section{MÉTODO CARTOGRÁFICO DE} PESQUISA-INTERVENÇÃO

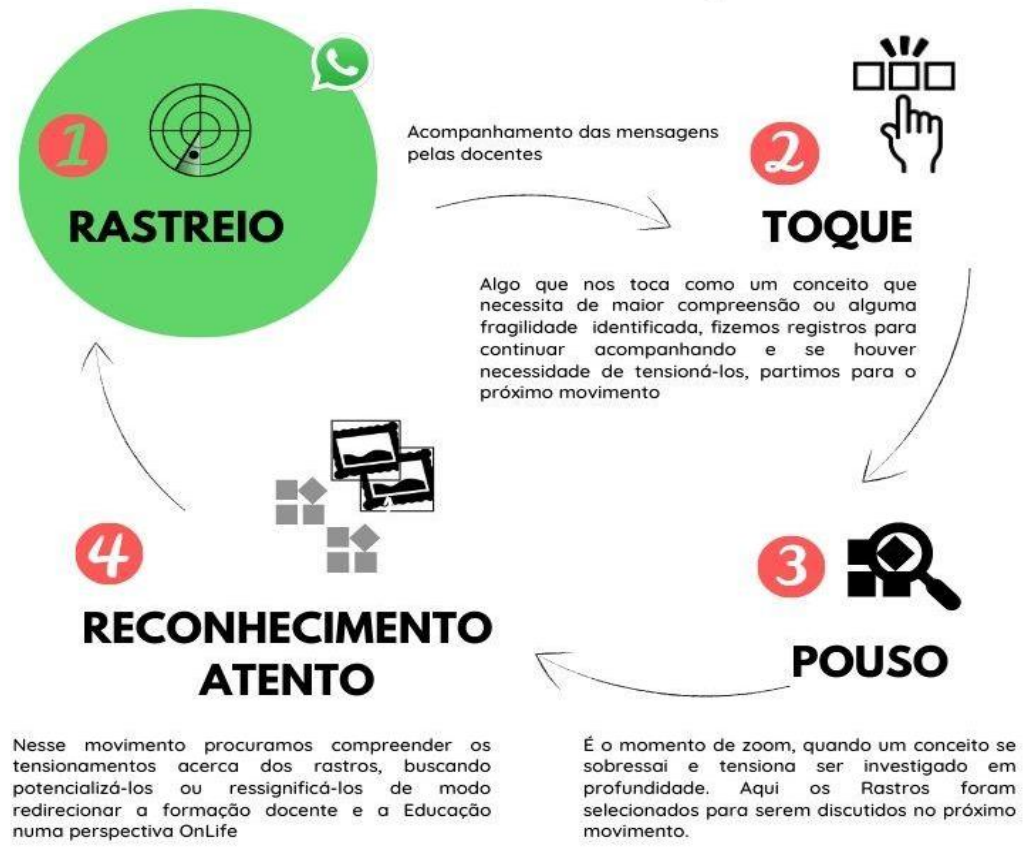

Fonte: Adaptada pelas autoras de Kastrup (2007).

O movimento de rastreio se caracteriza como uma exploração aberta e sem foco em um território, que se encontra em constante composição. No âmbito da pesquisa, esse movimento acontece diariamente por meio das leituras das mensagens que são postadas nos grupos do WhatsApp, das respectivas formações (professores da Educação Básica e Educação Superior, graduação e pós-graduação stricto sensu).

As pesquisadoras-cartógrafas, que atuam também como docentes nas formações, acompanham as postagens e realizam intervenções, mediando as dificuldades, problematizando as discussões, tensionando os conceitos e reorientando o percurso das formações. Sempre que algum aspecto se destaca, o movimento de toque é acionado, ou seja, esse é o movimento da atenção que aciona o processo de seleção. É a primeira significação, a primeira análise realizada sobre o movimento de rastreio.

Nesse movimento de rastreio, são selecionados fragmentos de diálogos postados pelos docentes nos grupos de WhatsApp que nos tensionam, enquanto cartógrafas, evidenciando que poderia haver a necessidade de um maior aprofundamento e maiores discussões em relação à algum conceito, que posteriormente chamamos de "rastros".

O pouso é o movimento que pode acontecer na sequência, em relação à atenção do cartógrafo e se configura enquanto o momento em que as pesquisadoras-cartógrafas realizam um zoom naquilo que foi identificado no movimento de toque, indicando que o elemento 
selecionado - fragmento de diálogo - precisa ser olhado mais de perto, para uma primeira análise. Isto é, "o gesto do pouso indica que a percepção, seja, ela visual, auditiva ou outra, realiza uma parada e o campo se fecha. Um novo território se forma, o campo de observação se reconfigura" (KASTRUP, 2007, p. 19).

No contexto desta pesquisa, o pouso se constituiu enquanto um olhar mais atento aos fragmentos de diálogos, que selecionamos no grupo do WhatsApp (explorados no rastreio e selecionados no toque), o que permitiu que as pesquisadoras-cartógrafas identificassem e definissem conceitos recorrentes nos diálogos dos docentes, aqueles que renderam discussões, problematizações e que, por vezes, foram propositivos para a reorientação do percurso das formações. Esses diálogos se apresentaram relevantes para nos ajudar a pensarmos acerca de uma Educação, em uma perspectiva OnLIFE. Em ambas as formações, entre os conceitos que identificamos enquanto rastros deixados pelos docentes, destacamos: espaço, tempo, aula, conteúdo, estudante, professor, avaliação, presença, TD, práticas pedagógicas e aprendizagem.

O reconhecimento atento é o quarto movimento da atenção do cartógrafo e se caracteriza por uma atitude investigativa sobre o pouso. Esse movimento nos reconduz aos rastros, no sentido de entender como e porque estes podem contribuir para melhor compreender o habitar do ensinar e do aprender - antes e durante a pandemia - e como os mesmos rastros, alinhados às problematizações do tempo presente, podem ser potencializados ou ressignificados de modo a desenvolvermos uma educação OnLIFE.

Enquanto movimento de reconhecimento atento, esse pressupõe a análise investigativa que as pesquisadoras cartógrafas realizam no território de observação. A partir dos conceitos problematizados pelos docentes nas formações, destacamos questões que foram levantadas por eles e cujas discussões os mesmos tensionaram, bem como reorientaram os percursos das formações e nos servem como pistas que nos ajudam a (re)pensar o período pós pandemia, os contextos educativos frente à complexidade em que estamos imersos; que nos instigam a inventar novos cenários, novos espaços para viver e conviver e até reconceituá-los, enquanto léxico. Essa análise e as potenciais discussões conexas acontecem nas seções seguintes deste documento.

\section{Habitar do Ensinar e do Aprender}

O território de observação que compõe a pesquisa contempla dois contextos formativos que correspondem a grupos de formação continuada: o primeiro ${ }^{8}$, iniciado em 2016, constituído

\footnotetext{
${ }^{8}$ Contexto formativo vinculado às pesquisas: 1) A cidade como espaço de aprendizagem: games e gamificação na constituição de Espaços de Convivência Híbridos, Multimodais, Pervasivos e Ubíquos para o desenvolvimento da
} 
por 104 professores e gestores de redes municipais de Educação Básica e; o segundo ${ }^{9}$, iniciado em 2018, constituído por 70 docentes (coordenadores e professores dos programas de pósgraduação stricto sensu - mestrados e doutorados) de diferentes escolas ${ }^{10}$, além de gestores e profissionais do apoio técnico da Unidade de Pesquisa e Pós-Graduação - UAPPG de uma universidade privada. Ambas as formações se encontram no contexto da "Educação e Cultura Digital diante da pandemia da COVID-19" e emergiram numa proposta de educação híbrida e multimodal (SCHLEMMER 2014, 2015, 2016, 2019; SCHLEMMER, MORETTI e BACKES, 2015; SCHLEMMER, BACKES e LA ROCCA, 2016; SCHLEMMER e MOREIRA, 2019).

Assim, no que tange às TD em rede, para viabilizar o desenvolvimento da formação nessa perspectiva foram escolhidos o Google Classroom, o Facebook e o WhatsApp para o primeiro grupo; para o segundo grupo, as TD institucionais: Ambiente Virtual de Aprendizagem Moodle, Microsoft Teams, WhatsApp; para ambos os grupos, outras TD foram apropriadas ao longo do percurso, conforme necessidade do que estava sendo desenvolvido.

A participação dos professores na formação ocorre por adesão, variando o nível de engajamento de cada um, bem como o tempo para que as aprendizagens ocorram. Participam ainda nos dois contextos formativos doutorandos voluntários e bolsistas de iniciação científica que atuaram, em diferentes momentos, como mediadores, problematizadores, facilitadores, pistas vivas, mentores, dentre outras possibilidades que possam surgir em função do movimento da formação.

$\mathrm{Na}$ primeira quinzena de março, diante da evidência do cancelamento das aulas presenciais físicas, os professores foram forçados a experimentar uma situação de isolamento físico, o que os colocou diante do desafio de (re)pensar, em caráter urgente e emergencial, a forma de desenvolver os processos de ensino e aprendizagem. Nesse sentido, a continuidade de ambos os processos formativos docentes - que estavam sendo desenvolvidos de forma híbrida e multimodal, com momentos presenciais físicos e presencial online, precisou ser repensada na modalidade totalmente online.

Cidadania (2016 - 2019), financiada pelo Chamada/Edital Universal Universal MCTI/CNPq n. 01/2016, processo n. 425903/2016-8 (SCHLEMMER, 2020b) e 2) A cidade como espaço de aprendizagem: Práticas Pedagógicas Inovadoras para a Promoção da Cidadania e do Desenvolvimento Social Sustentável (2019-2021), financiada pela Fundação Carlos Chagas e Itaú Social (OLIVEIRA, SCHLEMMER e MOREIRA, 2021).

${ }^{9}$ Contexto formativo vinculado à pesquisa "O urbano e o pós-urbano como espaços de aprendizagem: formação de professores e pesquisadores na cultura híbrida e multimodal”(2019-2021), financiada pelo edital Internacionalização FAPERGS. A formação relacionada a este projeto teve início com a extensão "Ecossistema de Educação na Pós-graduação: Cultura Híbrida e Multimodal” (2018-2020) (SCHLEMMER, KERSCH e OLIVEIRA, 2020) e, em julho de 2020, foi transformada no curso de Especialização Lato Sensu Educação Educação OnLIFE na Pós-Graduação Stricto Sensu (2020-2021).

${ }^{10}$ Escolas de Humanidades, Gestão de Negócios, Politécnica, Direito, Saúde, Indústria Criativa. 
A partir desse momento, discutiremos, então, o habitar do ensinar e do aprender em ambos contextos formativos relacionados ao período de março de 2020 até setembro de 2020 , portanto, em tempos pandêmicos, em que as formações passaram a ser desenvolvidas somente na modalidade online. A discussão será desenvolvida a partir dos rastros observados pelos movimentos da cartografia, os quais se relacionam à: espaço, tempo, presença, aula, estudante, professor, avaliação, TD, conteúdo, práticas pedagógicas e aprendizagem, deixados pelos participantes em ambos os contextos formativos.

Em relação ao contexto dos professores universitários, um primeiro movimento que evidenciamos, e que está relacionado ao rastro “TD”, partiu da instituição de ensino, enquanto gestão, no sentido de disponibilizar imediatamente após o cancelamento das atividades presenciais físicas: a) plataformas digitais institucionais tais como Moodle ${ }^{11}$ e Microsoft Teams por exemplo, a fim de possibilitar a continuidade das atividades educacionais de forma emergencial e b) apoio aos docentes com a oferta de treinamentos para 'o uso de' TD em rede.

Embora algumas plataformas fossem bastante conhecidas e já utilizadas pelos docentes da Pós-Graduação stricto sensu, como é o caso do Moodle, algumas de suas funcionalidades eram subutilizadas, uma vez que o mesmo é muitas vezes reduzido a um repositório de documentos (slides e textos). Essas tecnologias, quando utilizadas a partir de pedagogias mais diretivas com pouca interação ou imersão, não atendem àqueles professores que desejam desenvolver propostas educacionais mais interativas, imersivas e/ou inventivas. Isto nos leva a tensionar a concepção epistemológica que orienta o desenvolvimento tecnológico digital dessas plataformas (SCHLEMMER; DI FELICE, 2020), no sentido de que, ao proporcionarem um tipo específico de habitá-la, acaba por limitar ou direcionar a forma como os professores podem desenvolver suas práticas pedagógicas.

Os treinamentos para o 'uso de' TD que surgiram no grupo da Pós-Graduação stricto sensu, paralelos à formação que as autoras vinham desenvolvendo, se articularam na rede (web) e em redes de conhecimentos, motivados por diferentes atores: colegas da formação, equipe de formação pedagógica da instituição ${ }^{12}$ e também por parte dos estudantes. Esse primeiro movimento é significativo porque geralmente a primeira aproximação com as tecnologias digitais acontece pelo 'uso de' e, somente posteriormente, no sentido de 'apropriação para'.

Um segundo movimento pode ser observado por parte dos docentes universitários, em relação à busca pessoal por aprender a usar TD em rede, para além daquelas oferecidas pela instituição. Nesse sentido, na iminência da suspensão das aulas, na modalidade presencial física,

\footnotetext{
11 Já apropriado no contexto da formação que vem sendo desenvolvida pelas autoras.

12 Setor de formação docente que integra o Núcleo de Inovação Avaliação e Formação - NIAF da instituição.
} 
houve um período de tensão inicial, seguida de uma procura exponencial de professores interessados em integrar a formação docente que as autoras já desenvolviam, a fim de participar das discussões que estavam acontecendo acerca do processo de ensino que, naquele momento, só era possível ser desenvolvido no espaço online. A busca por TD em rede, por parte dos professores, se dá predominantemente no sentido de encontrar aquelas que atendiam a dois objetivos: a) promover comunicação com os estudantes (de preferência visual) e que, de forma rápida e fácil; b) permitissem disponibilização de materiais - conteúdos - para que os estudantes pudessem acessá-los.

Inferimos que a busca por uma comunicação visual e em modalidade síncrona foi uma iniciativa dos professores, no sentido de não perder a referência com o presencial físico e justificada pelos mesmos como a forma encontrada para manter o vínculo educacional e afetivo, tranquilizar os estudantes para o momento e ter a certeza da presença dos mesmos no processo educativo. A preocupação com a disponibilização dos materiais se apresenta associada aos rastros: conteúdo e aula, uma vez que, se percebe que para os docentes, se o conteúdo está disponibilizado na plataforma, o "conteúdo está sendo cumprido" e "aula está sendo dada", o que de certa forma mantêm a referência com a aula presencial física na qual o professor "oferta o conhecimento".

Um terceiro movimento pode ser inferido no sentido de compreensão do espaço online enquanto espaço plural, potencializador de um habitar do ensinar e do aprender em rede. Consideramos que, para além da aprendizagem de determinada tecnologia em rede, ao imergir no espaço online, o professor é projetado para um novo território onde o docente precisa aprender a habitar e a se comunicar. Estando em terra estranha, esse professor, tal como Alice metida no buraco, se questiona a respeito de vários conceitos. Nesse sentido, trazemos a articulação com outros rastros, tais como estudante, professor, conteúdo, aprendizagem, tempo e práticas pedagógicas.

A comunicação no espaço online, como um novo sistema de conversação, transforma radicalmente o espaço e o tempo, ou seja, os espaços ao invés de serem habitados enquanto lugares, são habitados enquanto fluxos (CASTELLS, 2013), e o chronos que rege o espaço online não é mais aquele conhecido pelo professor que se refere ao um espaço geograficamente delimitado, ou seja, físico, com presenças também físicas. Agora, esse tempo e espaço se hibridizam e se ampliam em espaços digitais em rede em um tempo síncrono e assíncrono.

Em relação a esse "outro" espaço, é possível perceber fortemente a ausência de uma compreensão acerca do habitar do ensinar e do aprender no mundo físico - dito real - e no 
mundo digital em rede - dito virtual ${ }^{13}$ - ou, por ora, compreensões equivocadas das diferenças substanciais entre conceitos como ensino remoto, ensino/educação a distância, educação online, educação digital, educação híbrida, entre outros. A evidência marcante desse momento se configura com a transposição de metodologias e práticas pedagógicas desenvolvidas no espaço físico geograficamente delimitado pela sala de aula, para o espaço digital de fluxos online, de conexões em rede.

No espaço de fluxos, os professores se questionam sobre qual é o seu "papel” nesse novo contexto educacional, uma vez que o "conhecimento"14, compreendido como o que era "passado" por eles aos estudantes, agora em rede, se encontra acessível e distribuído por diferentes entes com os quais interagimos e locais pelos quais nos deslocamos em movimentos nômades entre diferentes TD em rede. Aqueles professores que já vinham participando da formação continuada, se apropriando de diferentes TD e que, portanto, já desenvolviam práticas pedagógicas no espaço digital em rede, assumiram por vezes o papel de intermediadores pedagógicos, conforme o conceito de intermediação pedagógica múltipla (OKADA e OKADA, 2007), apoiando os colegas ${ }^{15}$ através da disponibilização de materiais, dicas e sugestões. Os estudantes também assumiram esse papel em alguns momentos, fortalecendo os vínculos entre os docentes e eles.

Os processos avaliativos, enquanto um quarto movimento evidenciado no percurso da formação, aparecem em um tempo diferenciado, quando relacionados aos outros rastros destacados, uma vez que os docentes demonstraram preocupação acerca das avaliações somente próximo ao período tradicionalmente especificado para que as avaliações acontecessem nas instituições, ou seja, ao final de um determinado ciclo. A avaliação também foi tensionada, em relação a outros pontos que nos instigam a pensar: a) o estudante se questiona como será avaliado; b) o professor questiona como avaliar e o que avaliar (conteúdo); c) a avaliação acontece durante todo o percurso e está relacionada ao ensinar e ao aprender, enquanto processo que precisa ser acompanhado, e não compreendida tão somente como uma fase, no final de um percurso e; d) a avaliação não precisa ser realizada sob o olhar controlador do professor, impossibilitando o acesso a materiais, tecnologias ou mesmo aos colegas.

\footnotetext{
${ }^{13}$ Virtual em oposição ao real; ressalte-se que, para as autoras, trata-se de dois modos de existência, de realidade, uma vinculada ao mundo físico e outra ao mundo digital que não são opostas, mas convivem e se complementam no universo, potencializando as relações entre diferentes entidades nessa realidade hiperconectada. O virtual é compreendido enquanto virtus, potência, portanto, passível se atualizar e se realizar tanto no mundo físico quanto no digital.

14 As falas dos professores evidenciam a conhecimento com sinônimo de informação, de conteúdo.

15 Esse apoio se deu por meio do setor de formação docente da instituição que integra o Núcleo de Inovação Avaliação e Formação - NIAF, pelos colegiados de cursos no âmbito das escolas da universidade, pela nossa formação - entre os colegas do grupo - e pela equipe de formação.
} 
Um quinto movimento acontece no sentido de que alguns professores foram em busca de diferentes TD, para além das plataformas institucionais, bem como foram ao encontro de metodologias e práticas pedagógicas para esse novo contexto educacional. Os grupos de formação docente continuada em rede, os quais se desenvolvem por meio de diferentes TD, tiveram relevância fundamental durante esse período e ao longo do processo de imersão dos docentes nesse novo, plural e potente espaço, uma vez que articularam saberes e fazeres em rede de diferentes áreas de conhecimento.

A seguir, abordaremos o habitar do ensinar e do aprender no contexto professores da Educação Básica. Nesse contexto, embora as atividades escolares com os estudantes estivessem suspensas, houve um movimento dos professores, já participantes da formação iniciada em 2016, em desenvolver uma maior apropriação das TD. Este primeiro movimento se intensificou e os temas da formação docente se ajustaram para atender às necessidades que se colocavam naquele momento inicial. Comparados ao grupo de professores universitários, os docentes da educação básica também realizaram movimento semelhante, ou seja, foram ao encontro de TD que promovessem a comunicação visual com os estudantes e que permitissem a disponibilização de materiais.

É importante mencionar que embora a Formação Docente estivesse sendo desenvolvida, de forma híbrida e multimodal, desde $2016^{16}$, havia uma variação quanto ao engajamento dos professores, uma vez que a mesma acontecia por adesão voluntária dos docentes e, portanto, sujeita a diferentes planos de força, tanto institucionais, quanto particulares. Com a pandemia, o grupo de professores se reorientou de outra forma, buscando o espaço da formação docente e intensificando as interações via grupo no WhatsApp. Assim, a formação docente foi retomada com um momento síncrono de apresentação e discussão da plataforma Google Classroom, uma vez que essa seria a tecnologia a ser adotada pelas escolas do município de São Leopoldo -RS, a fim de possibilitar a retomada das atividades educacionais.

O que pôde ser observado nesse momento, em relação aos docentes, foi um certo desconforto, dado que não havia uma orientação clara sobre a retomada das atividades nas escolas. Se somaram a isso as dificuldades do contexto socioeconômico dos estudantes, o que provocou questionamentos acerca da incerteza em relação ao acesso à rede $W i$-fi e a disponibilidade de equipamentos para a continuidade das aulas de forma online. A evidência que se tinha é que a tecnologia mais presente entre os estudantes era o smartphone e, com ele,

\footnotetext{
${ }^{16}$ No artigo Oliveira, Schlemmer e Moreira (2021) detalhamos como as formações foram sendo desenvolvidas, antes do período da pandemia.
} 
poderiam ter disponibilidade de aplicativos, acesso à vídeos e publicações nas mídias sociais digitais, desde que houvesse conexão.

Um segundo movimento foi observado no sentido da necessidade de aprender a 'usar' as TD que são populares entre os estudantes. Nesse sentido, a continuidade da formação docente na Educação Básica se desenvolveu na busca pela ampliação dos conhecimentos no que tange à produção e publicação de vídeos. Porém, observamos que as características de facilidade de uso e rápida aprendizagem eram desejáveis; por outro lado, aquelas tecnologias e práticas que demandavam um pouco mais de elaboração, eram muitas vezes rejeitadas. Evidenciamos nesse movimento uma predominância da transposição didática, na perspectiva de transmissão de mensagens e conteúdos para os estudantes. Outros pontos percebidos relacionados à condução do processo de formação indicavam que quanto mais acessíveis as TD, mais rapidamente os professores as experimentavam. E assim, quando um professor produzia um conteúdo advindo dessas TD, ao postar e compartilhar no grupo do WhatsApp, isto provocava muitas vezes o engajamento dos demais.

No período inicial da formação docente (durante a pandemia) percebemos um movimento intenso e diário, no grupo de WhatsApp, pois os professores da Educação Básica se apresentaram bastante interessados em compreender como se "usava" essa ou aquela tecnologia. Compreendemos que esse movimento se apresentou, pois os docentes tinham a intenção de estar preparados para a futura retomada das atividades com os estudantes, a partir de tecnologias que lhes fossem mais acessíveis e familiares.

Nesse contexto, um terceiro movimento começou a ser instigado pelo grupo de pesquisa responsável pela formação, no sentido de provocar os professores a compreender o que se modificava no habitar do ensinar e do aprender nesse novo espaço educacional constituído por diferentes TD em rede. Devido à maior familiarização do grupo de professores com as tecnologias digitais, observamos que um movimento de pertencimento, empatia, reciprocidade e apoio entre os participantes se fortalecia. Isso contribuiu significativamente para que os sentimentos iniciais de medo, rejeição e desconhecimento em relação ao desenvolvimento de práticas pedagógicas com TD em rede desaparecessem parcialmente. Nesse sentido se evidenciava um momento propício para problematizar o habitar do ensinar e o aprender em rede, em uma dimensão para além do uso da tecnologia como ferramenta e que contemplasse sua apropriação enquanto tecnologias da inteligência, na perspectiva de uma força ambiental.

Da habitação desse outro território emergia um sentimento de empoderamento do conhecimento em grupo e em rede, um movimento de ruptura com a transposição didática que dava lugar a outras práticas pedagógicas. Esse movimento se deu no sentido de instigar a 
construção de práticas pedagógicas que não levassem em consideração somente a presença de TD, mas também outros tempos, saberes e atores, objetivando a compreensão de um outro habitar do ensinar e aprender na construção de rede. Através das interações no WhatsApp, os professores foram problematizando suas práticas, se abrindo às discussões e compartilhando suas produções. Tal movimento se deu lentamente, respeitando o percurso, o ritmo e o momento de cada um dos docentes, se afastando da compreensão de aprendizagem enquanto cumprimento de tarefas, impostas por um cronograma uniforme e massificante estabelecido $a$ priori. O objetivo era que os professores compreendessem que não estavam ali para fazer um curso, entregar tarefas e obter um resultado final, mas, sim, se desenvolve, aprendendo em um grupo, vivendo e convivendo em rede.

Desse processo, um quarto movimento emergiu o qual mobilizou muitos professores para o compartilhamento de propostas de práticas pedagógicas, se articulando com seus pares e descobrindo/explorando outras TD em rede. Esses professores foram assumindo o papel de apoio para os outros colegas, criando materiais, dando sugestões, instigando-os na produção de suas práticas, buscando articular diversas áreas de conhecimento. Esse movimento exigiu muito dos formadores, uma vez que era necessário desconstruir a ideia de que, para a construção da prática pedagógica, era necessário o "domínio" da tecnologia, como algumas vezes foi mencionado pelos professores. Foi preciso discutir com o grupo a desconstrução da TD como uma "ferramenta", a fim de dar espaço a sua compreensão enquanto força e potência, que propicia o desenvolvimento de determinados conhecimentos, habilidades e competências. Acoplada aos conhecimentos da área específica, aos conhecimentos didático-pedagógicos e aos conhecimentos socioemocionais, as TD instigam um repensar das práticas pedagógicas, provocando em um operar inventivo, colaborativo e cooperativo entre estudantes, docentes, área de conhecimento, espaços, tecnologias, entre outros, ou seja, entre os vários atores que atuam no fazer pedagógico em e na rede.

Por último, um quinto movimento foi tomando forma: os professores começaram a atuar para fora do grupo do WhatsApp específico da formação, relatando como estavam auxiliando os pares que não participavam do grupo da formação docente, ou seja, redes dentro de redes estavam sendo criadas. Diariamente, postagens eram realizadas e propostas pedagógicas eram construídas e referenciadas para o desenvolvimento de colegas professores em vários contextos escolares, para além do grupo de formação docente no WhatsApp.

Os movimentos no habitar do ensinar e do aprender, identificados por meio dos rastros deixados pelos participantes em ambos os contextos formativos acima explicitados, fornecem pistas que nos permitem compreender que as diferentes TD em rede ocuparam espaço no 
território educacional, inicialmente como ferramentas a serem usadas para a reprodução e transposição de metodologias e práticas pedagógicas já conhecidas, não provocando assim, alteração significativa no habitar do ensinar e do aprender, os quais continuavam presos ao paradigma da Educação presencial física.

À medida em que os docentes, ao se familiarizarem mais com essas tecnologias, começavam a compreendê-las como potência e força em acoplamento com o fazer pedagógico, o habitar do ensinar e do aprender passava a ser problematizado. A compreensão de uso e apropriação de TD começava a ser discutida e conceitos como aula, sala de aula, tempo, espaço e presença lentamente, iam provocando alterações no habitar do ensinar e do aprender, promovendo um questionar/repensar das metodologias e práticas até então desenvolvidas enquanto transposição de um contexto educacional presencial físico, para um contexto híbrido e multimodal, ou ainda, online. Entendemos que é nesse estágio que ambos os grupos se encontram atualmente, obviamente com variabilidade entre os participantes.

De acordo com Schlemmer (2020a), Moreira e Schlemmer (2020) e Schlemmer, Di Felice e Serra (2020), os processos de ensino e de aprendizagem evidenciados pela abordagem do uso das TD pelos humanos - perspectiva do utilizador/consumidor - enquanto ferramenta, recurso e apoio gera uma consciência ingênua ${ }^{17}$ (PINTO, 2005) e dependência tecnológica digital (CASTELLS, 2013) e precisam ser superados. Essa superação implica uma abordagem de apropriação das TD, compreendidas enquanto Tecnologias da Inteligência (LÉVY, 1993), na qual o humano é produtor, numa perspectiva do empowerment e de desenvolvimento de uma consciência crítica $^{18}$ (PINTO, 2005) do mundo que habita (SCHLEMMER, 2020a). No entanto, ambas abordagens - uso e apropriação - estão relacionadas à uma compreensão antropocêntrica e sujeitocêntrica e, portanto também precisam ser superadas, uma vez que não dão conta das relações ecossistêmicas possibilitadas pelo ato conectivo, o qual pode conectar as biodiversidades e as inteligências dos dados, produzindo uma ecologia inteligente na qual os humanos são um dos membros, nem o centro e nem a periferia, mas coprodutores, conectando inteligências diversas num processo de transubstanciação (DI FELICE, 2017).

\section{Considerações Finais}

Com a pandemia da COVID-19, fomos transportados para um novo contexto educacional, no qual os processos de ensino e de aprendizagem já não podiam ser desenvolvidos no espaço geográfico, por meio de presenças físicas. Isso nos levou a questionar muitos dos

\footnotetext{
17 Aquela que é produzida pela dependência do uso de uma tecnologia produzida por outros.

${ }^{18}$ Produzida na autonomia e na apropriação da técnica, provocando empowerment.
} 
conceitos que tínhamos, tais como: aula, presença, tempo, espaço, conteúdo, estudante, professor, avaliação, presença, TD, práticas pedagógicas e aprendizagem. Com pouco conhecimento da potencialidade das TD em rede para os processos de ensino e de aprendizagem e, sem certeza alguma, imergimos nesse novo contexto. Ao vivenciá-lo, foram vários os estranhamentos e inúmeras as problematizações que emergiram no percurso, colocando em xeque nossas certezas. Foi no percurso que fomos superando nossas resistências e medos, na medida em que a única opção que tínhamos era conviver com as incertezas, explorar e experimentar. Era preciso nos dar o tempo de aprender no processo, com o erro, corrigindo rumos, enquanto inventávamos novas formas de ensinar e de aprender, buscando construir uma nova realidade na educação em rede, de forma simpoiética, ou seja, juntos, como nos ensina Haraway (2016), ao nos lembrar o caráter coletivo de toda criação e organização.

Os processos de ensino e aprendizagem precisam superar tanto as teorias instrucionistas, cuja centralidade está no conteúdo e no professor e que resultam em uma pedagogia diretiva, quanto a teoria da ação, centrada no sujeito e que resulta numa pedagogia ativa e, consequentemente, em metodologias e práticas também conhecidas como ativas. Essa superação implica na compreensão dos processos de ensino e de aprendizagem a partir da lógica de redes na qual, em lugar de uma teoria instrucionista ou ativa, temos o ato conectivo (DI FELICE, 2017) produzido nas interações ecossistêmicas entre humanos e não humanos atores-redes - que, ao entrar em relação de conectividade, expressam a dimensão impermanente e criadora (SCHLEMMER, DI FELICE e SERRA, 2020). Nessas interações ecossistêmicas, não há centralidade no processo educacional, mas há construção de redes que possibilitam a conexão com outras redes, desenhando uma arquitetura ecossistêmica. Isso nos instiga a pensar e criar pedagogias relacionais, conectivas e em rede, capazes de produzir metodologias e práticas inventivas, intervencionistas, reticulares e conectivas, num habitar atópico.

Superar as abordagens de uso e de apropriação das TD nos processos de ensino e de aprendizagem, ambos relacionados ao antropocentrismo e ao sujeitocentrismo, implica em pensar a educação em um movimento disruptivo que possibilite a invenção de desenhos reticulares nos quais as dualidades ${ }^{19}$ possam emergir. Esses desenhos reticulares, segundo Schlemmer (2020a), Moreira e Schlemmer (2020) e Schlemmer, Di Felice e Serra (2020), são expressos por uma terceira abordagem, a do acoplamento, enquanto agenciamento ${ }^{20}$, o qual

\footnotetext{
19 daquilo que é duplo em natureza, substância ou princípio.

20 Trata-se de relações entre componentes heterogêneos - físicos, biológicos, digitais, sociais, maquínicos, históricos, etc - nas quais não há determinismo ou previsibilidade (GUATTARI; ROLNIK, 1986). Ela não opera por meio da interiorização de "coisas" que lhe são exteriores, na medida em que tais "coisas" formam as composições que constituem a produção de subjetividade.
} 
opera por implicação recíproca entre movimentos heterogêneos que se constituem em rede, pelo ato conectivo transorgânico ${ }^{21}$. Essa abordagem nos parece mais apropriada para nos ajudar a compreender as relações ecossistêmicas, possibilitadas pelo ato conectivo, próprias do nosso tempo, e provocar o movimento disruptivo que precisamos na educação.

Essa nova compreensão possibilita pensar os processos de ensino e de aprendizagem na perspectiva da inventividade, enquanto percursos que se coengendram num habitar e co-habitar cada vez mais atópico, em contextos híbridos. Isso amplia, significativamente, a nossa condição habitativa, não mais vinculada somente aos espaços geográficos, mas também aos espaços digitais em rede que liga inteligências diversas. Dessa forma, temos territórios informacionais, comunicacionais e interacionais que modificam a nossa percepção de tempo, espaço e presença, dentre outros. Assim, é possível compreender a transformação digital enquanto deslocamento disruptivo num espaço-tempo de interações ecossistêmicas de inovação.

Papert já referia que "a descoberta não pode ser preparada; a invenção não pode ser planejada" (PAPERT, 1980, p. 143). Talvez a palavra que mais se adapte ao que estamos vivendo seja "bricolage", que Papert (1994) toma emprestado do antropólogo Lévi-Strauss para se referir a uma metodologia para a atividade intelectual que tem como princípios: use o que você tem, improvise, se vire.

Quando instituições educacionais, suas equipes diretivas, professores e estudantes, se lançam ao desafio da cultura digital em rede, também se projetam ao imprevisível e ao novo. E diante desse cenário, passam a usar diferentes TD, delas se apropriam e a elas se acoplam, se agenciando com diferentes plataformas digitais em rede ou até mesmo desenvolvendo plataformas, em uma perspectiva reticular e inventiva ${ }^{22}$ (SCHLEMMER; DI FELICE, 2020). Nesse ponto, começam a problematizar o próprio conceito de aula e de sala de aula. Entendemos que esse processo pode favorecer a emersão de práticas e metodologias e a cocriação de pedagogias e, assim, possibilitar a reinvenção das instituições de ensino em um contexto de realidade ou hiperrealidade educativa cada vez mais OnLIFE.

\section{REFERÊNCIAS}

ALVAREZ, Johnny; PASSOS, Eduardo. Cartografar é habitar um território existencial. In: KASTRUP, Virgínia; PASSOS, Eduardo; ESCÓSSIA, Liliana da (Org.). Pista do método da

21 conectando humano as biodiversidades, os objetos, os territórios e as inteligências dos dados (DI FELICE, 2017).

${ }^{22}$ A qualidade ecológica das interações em plataformas digitais na educação. 
cartografia: pesquisa-intervenção e produção de subjetividade. Porto Alegre: Sulina, 2015, p. 131-149.

BARROS, Letícia de; BARROS, Maria Elizabeth. O problema da análise em pesquisa cartográfica. In: PASSOS, Eduardo. KASTRUP, Virgínia; TEDESCO, Sílvia. Pista do método da cartografia: a experiência da pesquisa e o plano comum. Vol. 2. Porto Alegre: Sulina, 2016, p. 175-202.

CASTELLS, Manuel. A sociedade em rede: a era da informação, economia, sociedade e cultura. 6 ed. São Paulo: Paz e Terra, 2013.

DESCARTES, René. Discurso do Método. São Paulo: Wmf Martins Fontes, 2009.

DELEUZE, G.; GUATTARI, F. Mil platôs: capitalismo e esquizofrenia. Vol. 1.Tradução de Aurélio Guerra Neto e Célia Pinto Costa. Rio de janeiro: 34, 1995 (Coleção TRANS).

DI FELICE, Massimo. As redes digitais vistas a partir de uma perspectiva reticular. Revista do Instituto Humanitas Unisinos On-Line, São Leopoldo, p. 24-29, 2011. Disponível em: http://www.ihuonline.unisinos.br. Acesso em: 09 fev. 2021.

DI FELICE, Massimo. Entrevista com Massimo Di Felice. Eduardo Felipe Weinhardt Pires. Teccogs: Revista Digital de Tecnologias Cognitivas, TIDD | PUC-SP, São Paulo, n. 13, p. 7-19, jan-jun. 2016.

DI FELICE, Massimo. Net-ativismo: da ação social para o ato conectivo. São Paulo: Paulus, 2017. Coleção Comunicação.

DI FELICE, Massimo. Paisagens pós-urbanas: o fim da experiência urbana e as formas comunicativas do habitar. São Paulo: Annablume, 2009. Coleção Atopos.

FLORIDI, Luciano (Org.). The OnLIFEe manifesto: Being human in a hyperconnected era. London: Springer Open, 2015a. E-book. Disponível em: https://doi.org/10.1007/978-3-31904093-6. Acesso em: 09 fev. 2021.

FLORIDI, Luciano. Introduction. In: FLORIDI, Luciano (org.). The Onlife Manifesto: Being Human in a Hyperconnected Era. [S. 1.]: Springer Open, 2015b. p. 1-3. E-book. Disponível em: https://doi.org/10.1007/978-3-319-04093-6. Acesso em: 09 fev. 2021.

GUATTARI, Felix; ROLNIK, Suely. Micropolíticas: cartografias do desejo. Petrópolis, RJ: Vozes, 1986.

HARAWAY, Donna (2014). Staying with the trouble: Sympoiesis, String Figures, Multispecies Muddles. Keynote. Research-creation working group think-tank event. University of Alberta, Edmonton, Canadá. Disponível em https://www.youtube.com/watch?v=Z1uTVnhIHS8 Acesso em: 09 fev. 2021.

HARAWAY, Donna. Anthropocene, Capitalocene, Chthulhucene. Entrevista por Martha Kenney. In: DAVIS, Heather; TURPIN, Etienne (orgs). Art in the Anthropocene: Encounters Among Aesthetics, Politics, Environment and Epistemology. London: Open Humanities Press, 2015, p. 255-270. 
HARAWAY, Donna. Staying with the trouble: making kin in the Chthulucene. Durham; Londres: Duke University Press, 2016a.

HARAWAY, Donna. Antropoceno, capitaloceno, plantationoceno, chthuluceno: fazendo parentes. ClimaCom Cultura Científica, v. 3, n. 5, p. 139-146, 2016 b.

KASTRUP, Virgínia. Aprendizagem, Arte e Invenção. Psicologia em Estudo, Maringá, v. 6, n. 1, p. 17-27, jan./jun., 2001.

KASTRUP, Virgínia. O funcionamento da atenção no trabalho do cartógrafo. Psicologia \& Sociedade, Porto Alegre, v. 19, n. 1, p. 15-22, abr., 2007. Disponível em: https://doi.org/10.1590/s0102-71822007000100003. Acesso em: 09 fev. 2021.

KASTRUP, Vírgínia. A cognição contemporânea e a aprendizagem inventiva. In: KASTRUP, Virgínia; TEDESCO, Silvia; PASSOS, Eduardo (Org.). Políticas da Cognição. Porto Alegre: Sulina, 2015, p. 91-110.

LATOUR, Bruno. Reagregando o Social: uma introdução à teoria do Ator-Rede. Salvador: EDUFBA/EDUSC, 2012.

LATOUR, Bruno. Onde Aterrar? Como se orientar politicamente no Antropoceno. Rio de Janeiro: Bazar do Tempo, 2020.

LÉVY, Pierre. Cibercultura. Rio de Janeiro: 34, 1999.

MORIN. Edgar. Introdução ao pensamento complexo. Porto Alegre: Sulina, 2011.

MOREIRA, José António; SCHLEMMER, Eliane. Por um novo conceito e paradigma de educação digital OnLIFE. Revista UFG, Goiânia, v. 20, n. 26, p. 1-35, jan., 2020. Disponível em: https://doi.org/10.5216/revufg.v20.63438. Acesso em: 09 fev. 2021.

OLIVEIRA, Lisiane Cézar de; SCHLEMMER, Eliane; MOREIRA, José; Antonio. Aprendendo em Rede "na" e "com" a Cidade: diálogos entre Portugal e Brasil. Revista Educaonline, Rio de Janeiro, v. 15, n.1, p. 77-96, jan./abr., 2021. Disponível em: http://www.latec.ufrj.br/revistas lindex.php?journal=educaonline \&page $=$ article $\&$ op $=v i e w \& p a t h \% 5 B \% 5 \mathrm{D}=1161$. Acesso em: 09 fev. 2021.

OKADA, Alexandra; OKADA, Saburo. Novos Paradigmas na Educação Online com a Aprendizagem Aberta. In: V CONFERÊNCIA INTERNACIONAL DE TIC NA EDUCAÇÃO - CHALLENGES 2007, 2007, Braga. Anais da V Conferência Internacional de TIC na Educação. Braga: Universidade do Minho, 2007. p. 1-11.

PAPERT, Seymour. A máquina das crianças: repensando a escola na era da informática. Porto Alegre: Artes Médicas, 1994.

PAPERT, Seymour. Mindstorms: Children, Computers and Powerful Ideas. New York: Basic Books, 1980.

PINTO, Alvaro Vieira. O conceito de tecnologia. Vol I. Rio de Janeiro: Cantroponto, 2005. 
SCHLEMMER, Eliane. Gamificação em espaços de convivência híbridos e multimodais: design e cognição em discussão. Revista da FAEEBA - Educação e Contemporaneidade, Salvador, v. 23, n. 42, p. 73-89, jul./dez., 2014.

SCHLEMMER, Eliane. Mídia social em contexto de hibridismo e multimodalidade: o percurso da experiência na formação de mestres e doutores. Revista Diálogo Educacional, Curitiba, v. 15, n. 45, p. 399-421, maio/ago. 2015. Disponível em: https://doi.org/10.7213/dialogo.educ. 15.045.ds02. Acesso em: 09 fev. 2021.

SCHLEMMER, Eliane; MORETTI, Gaia; BACKES, Luciana. Spazi di convivenza ibrida e multimodale: ipotesi e sfide per l'apprendimento. QWERTY - Rivista Interdisciplinare di tecnologia, cultura e formazione, Roma, v. 10, n. 2, p. 78-91, 2015.

SCHLEMMER, Eliane; BACKES, Luciana; LA ROCCA, Fábio. L'Espace de coexistence hybride, multimodal, pervasif et ubiquitaire: le quotidien de l'éducation à la citoyenneté. Educação Unisinos (Online), v. 20, p. 297-306, 2016.

SCHLEMMER, Eliane. Games e Gamificação: uma alternativa aos modelos de EaD. RIED. Revista Iberoamericana de Educación a Distancia, Madri, v.19, n. 2, p. 107-124, 2016. Disponível em: https://doi.org/10.5944/ried.19.2.15731. Acesso em 09 fev. 2021.

SCHLEMMER, Eliane; MOREIRA, José António. Modalidade da Pós-Graduação Stricto Sensu em discussão: dos modelos de $\mathrm{EaD}$ aos ecossistemas de inovação num contexto híbrido e multimodal. Educação Unisinos, São Leopoldo, v. 23, n. 4, p. 689-708, out./dez., 2019. Disponível em: https://doi.org/10.4013/edu.2019.234.06. Acesso em 09 fev. 2021.

SCHLEMMER, Eliane. Dossiê: Educação em Contextos Híbridos e Multimodais. Educação Unisinos, São Leopoldo, v. 23, n. 4, p. 602-608, out./dez., 2019. Disponível em: https://doi.org/10.4013/edu.2019.234.ap2. Acesso em 09 fev. 2021.

SCHLEMMER, Eliane. Ecossistemas de Inovação na Educação na cultura híbrida e multimodal, 2020a. (Relatório de pesquisa como professora visitante sênior na Universidade Aberta de Portugal - UAb-PT, referente ao Edital No 01/2019 - Programa Institucional de Internacionalização - CAPES-PrInt - Processo Seletivo de Bolsas - 2019/1.

SCHLEMMER, Eliane. A cidade como espaço de aprendizagem: games e gamificação na constituição de Espaços de Convivência Híbridos, Multimodais, Pervasivos e Ubíquos para o desenvolvimento da Cidadania, 2020b. (Relatório de pesquisa, referente ao Edital: UNIVERSAL MCTI/CNPq No 01/2016. Número do Processo: 425903/2016-8.

SCHLEMMER, Eliane; KERSCH, Dorotéia; OLIVEIRA, Lisiane Cézar de. Formação de professores-pesquisadores em contexto híbrido e multimodal: desafios da docência no stricto sensu. Revista Tecnologias na Educação, v. 33, n. Edição Temática XIV, p. 1-23, dez., 2020. Disponível em: https://tecedu.pro.br/wp-content/uploads/2020/12/Art10-Ano-12-vol33Dezembro-2020.pdf. Acesso em: 09 fev. 2021.

SCHLEMMER, Eliane; FELICE, Massimo Di; SERRA, Ilka Márcia Ribeiro de Souza. Educação OnLIFE: a dimensão ecológica das arquiteturas digitais de aprendizagem. Educar em Revista, Curitiba, v. 36, e76120, 2020. Disponível em: https://doi.org/10.1590/01044060.76120. Acesso em: 09 fev. 2021. 
SCHLEMMER, Eliane; DI FELICE, Massimo. A qualidade ecológica das interações em plataformas digitais na educação. RELATEC Revista Latinoamericana de Tecnología Educativa, Badajoz, v. 19, n. 2, p. 207-222, 2020. Disponível em: https://doi.org/10.17398/1695-288x.19.2.207. Acesso em: 09 fev. 2021.

SERRES, M. Polegarzinha. Rio de Janeiro: Bertrand Brasil, 2013.

PASSOS, Eduardo; KASTRUP, Virgínia; ESCÓSSIA, Liliana da. Pistas do Método da Cartografia - Pesquisa: intervenção e produção de subjetividade. Vol.1. Porto Alegre: Sulina, 2015.

PASSOS, Eduardo; KASTRUP, Virgínia; TEDESCO, Silvia. Pistas do Método da Cartografia: A experiência da pesquisa e o plano comum. Vol. 2. Porto Alegre: Sulina, 2016.

PASSOS, Eduardo; BARROS, Regina Benevides de. A cartografia como método de pesquisaintervenção. In: PASSOS, Eduardo; KASTRUP, Virgínia; ESCÓSSIA, Liliana da (org.). Pista do método da cartografia: pesquisa-intervenção e produção de subjetividade. 4a reimp ed. V.1. Porto Alegre: Sulina, 2015, p. 17-31.

RODRIGUES, Heliana de Barros Conde. Analisar. In: FONSECA, Tania Galli; NASCIMENTO, Maria Lívia do; MARASCHIN, Cleci (Orgs.) Pesquisar na Diferença: um abecedário. Porto Alegre: Sulina, 2012. p. 39.

\section{SOBRE AS AUTORAS:}

\section{Eliane Schlemmer}

Pós-Doutora em Educação (UAb-Portugal), Doutora em Informática (UFRGS). Professorapesquisadora titular do PPG em Educação e PPG em Linguística Aplicada (UNISINOS). Líder do Grupo de Pesquisa Educação Digital - GPe-dU UNISINOS/CNPq. Bolsista PQ/CNPq (nível 1D).E-mail: elianes@unisinos.br

(iD https://orcid.org/0000-0001-8264-3234

\section{Lisiane Cézar de Oliveira}

Mestre em Ciências da Computação pela Universidade Federal de Santa Catarina (UFSC); Professora do Instituto Federal de Educação, Ciência e Tecnologia do Rio Grande do Sul (IFRS), campus Ibirubá/RS. Membro do Grupo de Pesquisa Educação Digital (GPedU) UNISINOS/Cnpq. E-mail: guba30@gmail.com

(ID) https://orcid.org/0000-0003-1909-3545

\section{Janaína Menezes}

Mestre em Educação pela Universidade do Vale do Rio dos Sinos (UNISINOS). Doutorando em Educação pela UNISINOS. Professora de Língua Inglesa na Educação Básica - IENH. Membro do Grupo de Pesquisa Educação Digital (GPedU) UNISINOS/CNPq. E-mail: janamenezes73@gmail.com (iD) https://orcid.org/0000-0002-6789-6951 